\title{
Under-reporting in dietary surveys - implications for development of food-based dietary guidelines
}

\author{
W Becker ${ }^{1, *}$ and D Welten ${ }^{2}$ \\ ${ }^{1}$ National Food Administration, Uppsala, Sweden: ${ }^{2}$ TNO Nutrition, Zeist, the Netherlands
}

\begin{abstract}
Objective: To illustrate issues related to under-reporting in dietary surveys relevant for development of food-based dietary guidelines

Setting: Food and nutrient intakes in two national dietary surveys are analysed in relation to under-reporting using the concept of cut-off values for the ratio between energy intake and basal metabolic rate as well as biochemical markers of nutritional status.

Results: Subjects with an implausibly low EI/BMR ratio had dietary patterns more close to recommended levels, e.g. lower fat intake and higher fibre intake, than those with acceptable energy intakes. Intakes of micronutrients were lower. This was due to both general and selective under-reporting of foods. Under-reporting was due to less frequent consumption, larger proportion of non-consumers and smaller portion sizes. Low EI/BMR ratios did not influence the characterisation of protein and micronutrient intake of low and high consumers of fruit and vegetable intake.

Conclusions: Under-reporting can influence the usefulness of dietary data as a tool for developing food-based dietary guidelines, and the extent of under-reporting should be assessed using appropriate methods.
\end{abstract}

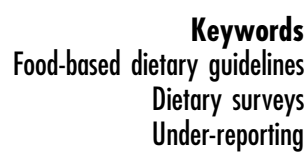

\section{Introduction}

Knowledge of the population's dietary habits is necessary in the development of food-based dietary guidelines (FBDG). Valid food consumption data, representative for the target population, should be the ideal. However, most dietary survey methods have been found to produce energy intake levels that are below expected needs, indicating under-reporting of the food intake or undereating, i.e. a decreased food intake during the period of the study. The extent of under-reporting can be estimated using the concept of 'cut-off values', which is based on the ratio between the observed energy intake and the estimated BMR (EI/BMR est $)$ for a specified energy expenditure level. A ratio of 1.35 is considered to indicate the lowest value for habitual energy intake of an individual that is compatible with a normal (not bedbound) life-style. For an individual the cut-off value for probable under-reporting depends on the number of days the survey covers and the energy expenditure level. A recent analysis, based on the concept of cut-off values, of national surveys from five European countries using different methodologies indicated that gross underreporting of energy intake occurred among 8-29\% of the subjects. Another 10-29\% reported energy intakes that were classified as dubious ${ }^{2}$. Suspected under-reporting can also be evaluated using biochemical indicators of nutritional status.

Under-reporting in dietary surveys can be general under-reporting of the food intake, selective underreporting of certain foods, or both. Certain meals such as snacks and in-between-meals might be under-reported leading to systematic underestimation of the consumption of foods regarded as less 'healthy'. On the other hand, consumption of foods regarded as healthy might be overestimated among certain individuals.

In this paper data from two national dietary surveys were used to illustrate some problems associated with under-reporting in the context of the development of FBDG. The following aspects were investigated: gross dietary composition, micronutrient intake, high and low consumers and selective under-reporting of foods.

\section{Material and methods}

Data from two dietary surveys were used, the first Swedish national dietary survey $1989^{3-5}$, and the Dutch Micronutrient Status Study ${ }^{6}$.

The first Swedish national survey (the 'HULK survey') was carried out in $1989^{3}$. The survey was a combined household and dietary survey of the Swedish population and was carried out by Statistics Sweden in collaboration 
with the National Food Administration (NFA). Each household was asked to record all the foods it purchased over a 4-week period. Food consumption for one household member was measured using a simplified 7day record with precoded alternatives (expressed in household measures) for food consumed. Using a portion-guide with photographs, sizes of cooked food portions eaten at main meals and fat spreads used on sandwiches could be estimated. Approximately 2000 persons, 1-74 years old, completed the study with a participation rate of $70 \%$. In the analysis, data from the individual dietary survey for subjects aged $15-74$ yr. $(n=$

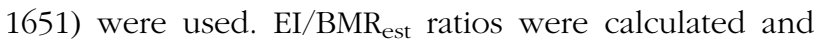
subjects classified in three categories according to ratios: $<1.10$ (implausibly low energy intake), 1.10-1.34 (dubiously low energy intake) and $>1.35$ (acceptable energy intake). Body weights were self-assessed and BMR was calculated using a modified Schofield equation given in $^{8}$. Twenty-six percent of the subjects were classified as having an implausibly low energy intake, 27 percent as having dubiously low intakes and 46 percent as having acceptable intakes 5 .

In the Dutch Micronutrient Status Study ${ }^{6}$ nutritional status indicators were collected among 300 Dutch adults (20-79 years of age). Furthermore, dietary intake was assessed in a comparable way as in the second Dutch National Food Consumption Survey (DNFCS) ${ }^{7}$, except a 3-day food record instead of a 2-day food record was used. On the basis of the formulae published by Goldberg et $a l .{ }^{1}$, an average EI/BMR ratio of 1.51 was calculated as the minimal expected value for a study population of 300 persons leading a sedentary life. For evaluation of individual data, a cut-off value of 1.04 was used for the EI/BMR ratio ${ }^{1}$. Protein intake was assessed by measuring nitrogen excretion in urine. Plasma concentration of ascorbic acid was measured as a reliable indicator of vitamin C status. The plasma PLP (pyridoxal 5'-phosphate) level and urinary 4-PA (4-pyridoxic acid) were determined, which are both sensitive status parameters for vitamin B6. Urine samples were collected on the third day of recording and blood samples one day later. This provided a good opportunity to compare biomarker values with relevant intake values.

\section{Results and discussion}

\section{Diet characterisation}

An important step in the development of FBDG is to assess the proportion of the target population whose diet meets or is close to the various recommendations and to describe that diet in terms of foods, meal patterns etc.

The data from the Swedish survey show that subjects reporting implausibly low energy intakes had lower mean intakes of total and saturated fat, but higher mean intakes of protein and dietary fibre (expressed as energy percent, $\mathrm{E} \%$ ), than of those reporting an acceptable energy intake, indicating a more favourable dietary composition ${ }^{5}$. Data for total fat are shown in Fig. 1. Similar results were reported by Haraldsdóttir et $a l^{2}$. If this is not accounted for, the proportion of the population meeting the recommendations will be overestimated, which could affect priorities for the development of FBDG.

For micronutrients, under-reporting might lead to an overestimation of the proportion of the population not meeting a certain recommendation or target intake. This is illustrated with data from the Swedish survey (Table 1). The table shows that the proportion of men and women that have vitamin intakes below the average requirements ${ }^{9,10}$ decreases substantially if subjects with implausibly or dubiously low energy intakes are excluded.

In a similar way under-reporting might bias conclusions about food consumption patterns compatible with

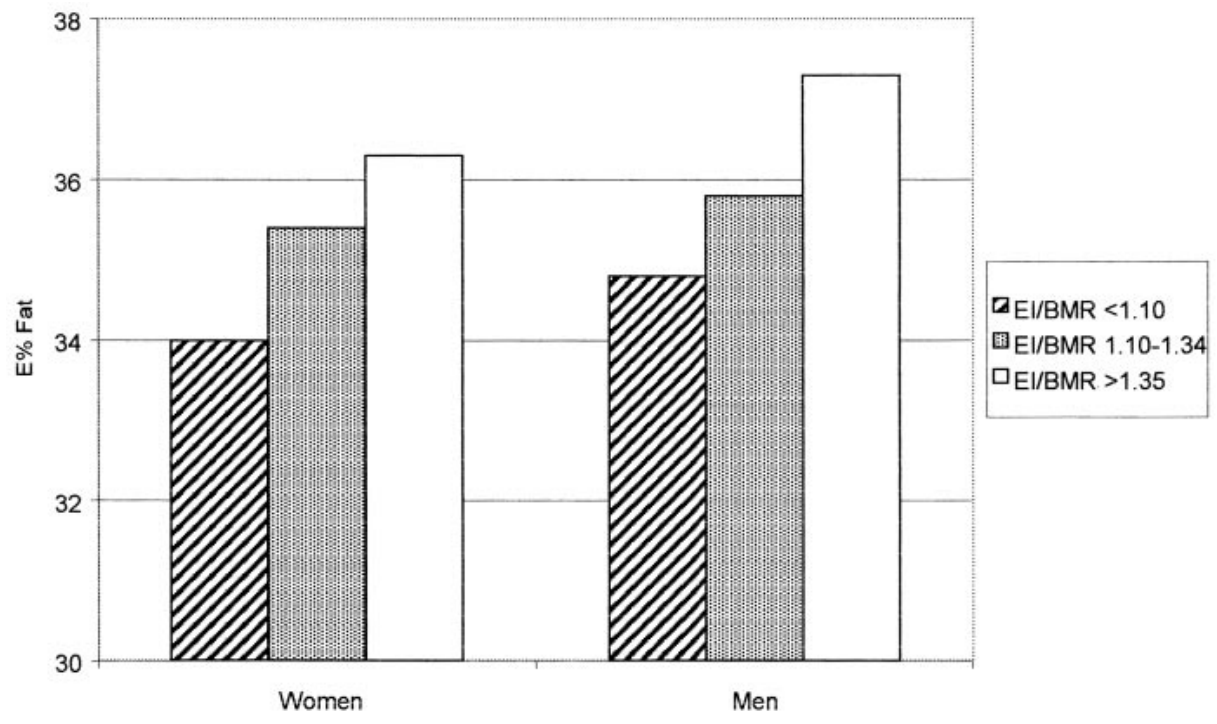

Fig. 1 Energy percent total fat in diets according to El/BMR categories among Swedish adults ${ }^{5}$ 
Table 1 Percentage proportion of subjects with mean daily nutrient intakes below average requirement among Swedish men and women

\begin{tabular}{|c|c|c|c|c|c|}
\hline & \multicolumn{2}{|c|}{ Mean intake } & \multirow[b]{2}{*}{$\mathrm{AR}^{*} \mathrm{~m} / \mathrm{w} \dagger$} & \multirow[b]{2}{*}{$\%<\mathrm{AR}$, all subjects, $\mathrm{m} / \mathrm{w}$} & \multirow[b]{2}{*}{$\%<\mathrm{AR}, \mathrm{El} / \mathrm{BMR} \S>1.35 \mathrm{~m} / \mathrm{w}$} \\
\hline & Men & Women & & & \\
\hline Vitamin A, RE & 1730 & 1380 & $750 / 700$ & $13 / 17$ & $2 / 4$ \\
\hline Vitamin $D, \mu g$ & 7.0 & 4.9 & $5 \ddagger$ & $34 / 65$ & $12 / 44$ \\
\hline Vitamin $\mathrm{C}, \mathrm{mg}$ & 76 & 80 & 30 & $12 / 11$ & $6 / 4$ \\
\hline Thiamin, mg & 1.6 & 1.2 & $1.1 / 0.9$ & $15 / 20$ & $1 / 2$ \\
\hline Riboflavin, mg & 2.3 & 1.8 & 1.4/1.1 & $17 / 13$ & $2 / 1$ \\
\hline Niacin, NE & 37 & 27 & $15 / 12$ & $<1 /<1$ & $0 / 0$ \\
\hline Vitamin $\mathrm{B}_{6}, \mathrm{mg}$ & 2.3 & 1.8 & $1.3 / 1.0$ & $6 / 5$ & $0 / 0$ \\
\hline Vitamin $B_{12}, \mu g$ & 9.3 & 6.8 & 1.4 & $<1 /<1$ & $0 / 0$ \\
\hline Folate, $\mu \mathrm{g}$ & 247 & 209 & $140 / 120$ & $8 / 8$ & $<1 /<1$ \\
\hline
\end{tabular}

* Average requirement ${ }^{9,10}$

$\dagger \mathrm{m} / \mathrm{w}$ : data for men and women, respectively.

$\ddagger$ Recommended daily intake ${ }^{9,10}$

$\S$ Ratio between reported energy intake and estimated basal metabolic rate.

guidelines. Table 2 shows that consumption of most foods among subjects with implausibly low energy intakes was lower than among acceptable reporters. However, after correcting for energy intake among low reporters the consumption of several foods were similar or even higher than among acceptable reporters, e.g. cheese, potatoes, fruit, vegetables and meat (Table 2).

If under-reporting of energy and food intakes is not taken into account biased dietary advice or other nutrition policy actions may be planned.

\section{High and low consumers}

Comparison of high and low consumers (upper and lower centiles) of nutrients and foods is a technique commonly used in FBDG development. This can be used to identify the dietary pattern of groups conforming to one or several desirable dietary characteristics in terms of foods and nutrients. Under-reporting might bias results of such analyses affecting the formulation of FDBG.

In the Swedish survey subjects consuming a diet with a low saturated fat (lower quartile, $<13 \mathrm{E} \%$ ) content ate less spreads, cheese, sausage and buns, whereas the intake of fruit and vegetables was substantially higher, compared to subjects eating a high saturated fat diet (upper quartile $>18 \mathrm{E} \%$, Table 3). The average energy intake and EI/BMR ratio were however lower, indicating that the proportion of subjects with probable under-reporting was higher in the low saturated fat group than in the high saturated fat group. This suggests that the dietary pattern in the low saturated fat group does not reflect food consumption compatible with long-term maintenance. The data can however be used as a basis for FBDG after adjustment to a reasonable energy level as exemplified in Table 3. Further information characterising the nature of under-reporting, e.g. regarding selectivity and actual under-eating would however be valuable.

In the Dutch Micronutrient Status Study ${ }^{6}$ the subjects were divided into tertiles with respect to fruit and vegetable consumption (Table 4). The diet of subjects in the lower tertile of fruit and vegetable consumption was

Table 2 Food intake (observed and energy adjusted) among Swedish women with implausibly low and acceptable energy intake in relation to provisional dietary guidelines

\begin{tabular}{|c|c|c|c|c|}
\hline & \multicolumn{2}{|c|}{$\begin{array}{c}\text { Implausibly low energy } \\
\text { intake El:BMR }<1.1(n=226)\end{array}$} & $\begin{array}{l}\text { Acceptable energy intake } \\
\text { El:BMR }>1.35(n=373)\end{array}$ & $\begin{array}{l}\text { Dietary } \\
\text { guidelines* }\end{array}$ \\
\hline Energy, $\mathrm{MJ} / \mathrm{d}$ & \multicolumn{2}{|c|}{5.5} & 9.3 & 9.2 \\
\hline $\mathrm{El} / \mathrm{BMR}_{\mathrm{est}}$ & \multicolumn{2}{|c|}{0.92} & 1.66 & 1.60 \\
\hline Food consumption & $g / d$ & $\mathrm{~g} / 9.2 \mathrm{MJ}$ & $\mathrm{g} / 9.2 \mathrm{MJ}$ & \\
\hline Spreads & 10 & 17 & 20 & 20 \\
\hline Cheese & 29 & 49 & 44 & 30 \\
\hline Milk & 265 & 447 & 400 & 400 \\
\hline Bread & 63 & 106 & 97 & 150 \\
\hline Potatoes & 84 & 142 & 124 & 150 \\
\hline Vegetables & 82 & 138 & 105 & 200 \\
\hline Fruit & 112 & 189 & 150 & 230 \\
\hline Juice & 47 & 79 & 85 & 50 \\
\hline Meat & 66 & 111 & 81 & 80 \\
\hline Sausage & 14 & 24 & 22 & 15 \\
\hline Buns, pastry, etc & 24 & 41 & 58 & $<10$ \\
\hline Ice-cream & 10 & 17 & 19 & - \\
\hline Sweets & 3 & 6 & 13 & - \\
\hline
\end{tabular}

\footnotetext{
* Provisional guidelines.
} 
Table 3 Mean intakes of energy and selected foods among Swedish women aged 15-74 years classified as low or high saturated fat eaters

\begin{tabular}{lccc}
\hline & $\begin{array}{c}\text { Low SFA } \\
\text { Actual intake }\end{array}$ & $\begin{array}{c}<13 \text { E\% } \\
\text { Energy adjusted }\end{array}$ & High SFA $>18$ E\% \\
\hline Energy, MJ/d & 6.7 & 8.3 & 8.3 \\
El:BMR ratio & 1.16 & - & 1.48 \\
Food consumption, g/d & & & \\
Spreads & 9 & 11 & 25 \\
Cheese & 26 & 32 & 46 \\
Milk & 341 & 422 & 368 \\
Bread & 77 & 95 & 85 \\
Potatoes & 107 & 133 & 809 \\
Vegetables & 123 & 152 & 97 \\
Fruit & 188 & 111 & 44 \\
Juice & 90 & 87 & 73 \\
Meat & 70 & 15 & 21 \\
Sausage & 12 & 40 & 50 \\
Buns, pastry etc. & 32 & & \\
\hline
\end{tabular}

lower in protein, vitamin $\mathrm{C}$ and vitamin $\mathrm{B} 6$ than the diet of subjects in the upper tertile (Table 4). The diet of low fruit and vegetable consumers also was higher in fat, but lower in carbohydrate and fibre. Energy intake and the overall EI/BMR ratio in the lower tertile was lower (1.42) than the study-specific cut-off point of 1.51 and the percentage of subjects with a ratio below the individual cut-off point of
1.04 was relatively high (19\%). This could be indicative of the occurrence of under-reporting of energy intake in the lower tertile of fruit and vegetable intake.

With regard to protein intake, the difference between protein intake and urinary protein was not significantly different from zero in all three tertiles, which seems to indicate no under-reporting of protein intake. Furthermore,

Table 4 Mean energy and nutrient intake and status according to tertiles of fruit and vegetable intake $(\mathrm{g} / \mathrm{day})$ in the Dutch Micronutrient Status Study ${ }^{6}$

\begin{tabular}{|c|c|c|c|c|}
\hline Fruit \& vegetable consumption. $\mathrm{g} / \mathrm{d}$ & $\begin{array}{c}\text { Low }(n=99) \\
<236\end{array}$ & $\begin{array}{c}\text { Medium }(n=101) \\
236-366\end{array}$ & $\begin{array}{c}\text { High }(\mathrm{n}=100) \\
>367\end{array}$ & Signt \\
\hline \multicolumn{5}{|l|}{ Energy } \\
\hline -intake (MJ/day) & 9.2 & 9.9 & 9.8 & \\
\hline -El/BMR & 1.42 & 1.52 & 1.51 & \\
\hline -El/BMR<1.04 (\%) & 19.2 & 5.9 & 7.0 & $p<0.01$ \\
\hline \multicolumn{5}{|l|}{ Protein (g/day) } \\
\hline -vegetable & 27 & 33 & 35 & $p<0.001$ \\
\hline -animal & 52 & 57 & 55 & \\
\hline -total & 79 & 91 & 90 & $p<0.001$ \\
\hline -urinary excretion & 81 & 91 & 87 & $p<0.001$ \\
\hline Fat intake (en\%) & 37 & 37 & 35 & $p<0.001$ \\
\hline $\mathrm{CHO}$ intake (en\%) & 43 & 43 & 46 & $p<0.001$ \\
\hline Fiber intake (g/day) & 14 & 18 & 21 & $\mathrm{p}<0.001$ \\
\hline Alcohol intake (en\%) & 4.6 & 4.4 & 3.5 & \\
\hline \multicolumn{5}{|l|}{ Vitamin $\mathrm{C}^{*}$} \\
\hline -intake (mg/day) & 66 & 83 & 115 & $p<0.001$ \\
\hline -conc. $(\mu \mathrm{mol} / \mathrm{l})$ & 43 & 54 & 53 & $p<0.01$ \\
\hline \multicolumn{5}{|l|}{ Vitamin B6 intake* } \\
\hline$-\mathrm{mg} /$ day & 1.54 & 1.76 & 1.85 & $p<0.001$ \\
\hline$-\mathrm{mg} / \mathrm{MJ}$ & 0.71 & 0.76 & 0.82 & $p<0.01$ \\
\hline$-\mu \mathrm{g} / \mathrm{g}$ protein & 19 & 20 & 21 & \\
\hline \multicolumn{5}{|l|}{ Vitamin B6 status* } \\
\hline -plasma PLP (nmol/l) & 36 & 40 & 53 & $p<0.001$ \\
\hline -urinary 4PA (mg/24h) & 0.80 & 0.85 & 1.01 & $p<0.01$ \\
\hline
\end{tabular}

* Supplement users were excluded. Number of subjects in low, medium and high tertile were 67,74 , and 63 respectively. † Analysis of variance. 
the results demonstrate that the dietary intake and status indicators of energy, protein, vitamin $\mathrm{C}$ and vitamin B6 were higher at a higher consumption level of fruit and vegetables. This is probably the result of the more general phenomenon that a higher consumption of a particular food group, in this case fruit and vegetables, is more likely to be realised by subjects with a higher energy requirement. Despite of the observed differences in energy intake and $\mathrm{EI} / \mathrm{BMR}$ ratio, the differences in the intake of protein, vitamin $\mathrm{C}$ and vitamin $\mathrm{B} 6$ are confirmed by the biomarkers of exposure. These data support that the under-reporting of energy intake did not influence the characterisation of protein and micronutrient intake of high and low consumers of fruit and vegetables. Furthermore, the data might not be explained by actual undereating because the intake values of protein, vitamin $\mathrm{C}$ and vitamin B6 are comparable with the intake values of the second Dutch National Food Consumption Survey.

\section{General and selective under-reporting}

According to the Swedish study, the consumption of most foods was lower among subjects classified as low reporters than among acceptable reporters. In case of

Table 5 Food consumption and portion sizes among Swedish men and women 15-74 yr. old classified according to El/BMR est ratios. Mean values

\begin{tabular}{|c|c|c|}
\hline & \multicolumn{2}{|c|}{$\mathrm{El} / \mathrm{BMR}_{\mathrm{est}}$} \\
\hline & $<1.10$ & $>1.35$ \\
\hline \multicolumn{3}{|l|}{ Men } \\
\hline Vegetables, g/d & 61 & 83 \\
\hline Vegetables, frq/d* & 1.12 & 1.47 \\
\hline Portion size, $\mathrm{g}$ & 54 & 56 \\
\hline$\%$ consumers & 94 & 98 \\
\hline Fruit, g/d & 86 & 120 \\
\hline Fruit, frq/d & 0.75 & 1.04 \\
\hline Portion size, $\mathrm{g}$ & 115 & 115 \\
\hline$\%$ consumers & 79 & 93 \\
\hline Spread, g/d & 15 & 42 \\
\hline Spread, frq/d & 1.46 & 2.27 \\
\hline Portion size, $\mathrm{g}$ & 10 & 19 \\
\hline$\%$ consumers & 91 & 96 \\
\hline \multicolumn{3}{|l|}{ Women } \\
\hline Vegetables, g/d & 75 & 94 \\
\hline Vegetables, $\mathrm{frq} / \mathrm{d}$ & 1.55 & 1.90 \\
\hline Portion size, g & 48 & 49 \\
\hline$\%$ consumers & 98 & 100 \\
\hline Fruit, g/d & 111 & 151 \\
\hline Fruit, frq/d & 1.02 & 1.45 \\
\hline Portion size, $\mathrm{g}$ & 109 & 104 \\
\hline$\%$ consumers & 89 & 98 \\
\hline Spread, g/d & 10 & 20 \\
\hline Spread, frq/d & 1.37 & 2.02 \\
\hline Portion size, g & 7 & 10 \\
\hline$\%$ consumers & 92 & 98 \\
\hline
\end{tabular}

* Consumption frequency per day. fruit and vegetables, this was due to less frequent consumption and for fruit also a larger proportion of subjects reporting no intake during the survey period (nonconsumers). Portion sizes were however similar among low and acceptable reporters (Table 5). For spreads underreporting was associated with both less frequent consumption and smaller portions (Table 5). Foods consumed as snacks, e.g. sweets, buns and cakes, were under-reported to a larger extent than foods regarded as more healthy, e.g. fruit and vegetables (see Table 2).

In summary, gross under-reporting can influence the usefulness of dietary data as a basis for developing foodbased dietary guidelines, especially for determining which dietary changes are most desirable and which are more or less easy to attain. It can also bias food-based dietary guidelines in terms of realistic portion sizes and consumption frequencies for various foods. Classification into high and low consumers is a useful tool in the development of food-based dietary guidelines, but underreporting may bias observed differences.

\section{References}

1 Goldberg GR, Black AE, Jebb SA, Cole TJ, Murgatroyd PR, Coward WA, Prentice AM. Critical evaluation of energy intake data using fundamental principles of energy physiology: 1. Derivation of cut-off values to identify under-reporting. Eur. J. Clin. Nutr. 1991; 45: 569-81.

2 Haraldsdóttir J, Becker W, Hulshof K, Johansson L, HermannKunz E. Assessment of vitamin and mineral adequacy may be biased by implausibly low energy intakes. Results from five European countries. Abstract. Eur. J. Clin. Nutr. 1999; 52(Suppl. 2): S82.

3 Becker W. Food habits and nutrient intake in Sweden 1989 (in Swedish with English summary). National Food Adminstration, Uppsala: 1994.

4 Becker W. Dietary guidelines and patterns of food and nutrient intake in Sweden. Br. J. Nutr. 1999; 82(Suppl. 2): S113-7.

5 Becker W, Foley S, Shelley E, Gibney M. Energy underreporting in Swedish and Irish dietary surveys: implications for food-based dietary guidelines. Br. J. Nutr. 1999; 81(Suppl. 2): $\mathrm{S} 127-31$.

6 Brussaard JH, Brants HA-M, Löwik MRH. Nutritional status among adults with special reference to micronutrients (Dutch Nutrition Surveillance System). Eur. J. Clin. Nutr. 1997; 51(suppl. 3): S1-66.

7 Löwik MRH, Hulshof KFAM, Van der Heijden LJM, Brussaard JH, Burema J, Kistemaker C, De Vries PJF. Changes in the diet in the Netherlands 1987-1988 to 1992 (Dutch Nutrition Surveillance System). International Journal of Food Sciences and Nutrition 1998; 49(suppl. 1): S1-68.

8 Commission of the European Communities. Reports of the Scientific Committe for Food (Thirty-first series). Nutrient and energy intakes for the European Community. Luxembourg, 1993.

9 Sandström B, Lyhne N, Pedersen JI, Aro A, Thorsdóttir I, Becker W. Nordic Nutrition Recommendations. Scand. J. Nutr./Näringsforskning 1996; 40: 161-5.

10 Sandström B, Lyhne N, Pedersen JI, Aro A, Thorsdóttir I, Becker W. Nordiska Näringsrekommendationer 1996 (Nordic Nutrition Recommendations). Copenhagen: Nordic Council of Ministers, Nord, 1996: 28. 